\title{
MODELO PARA O DIMENSIONAMENTO E A LOCAÇÃO DE SISTEMAS DE TERRACEAMENTO EM NÍVEL
}

\section{NORI P. GRIEBELER ${ }^{1}$, FERNANDO F. PRUSKI ${ }^{2}$, ALESSANDRO F. TEIXEIRA ${ }^{3}$, DEMETRIUS D. DA SILVA ${ }^{4}$}

\begin{abstract}
RESUMO: A erosão hídrica é um dos principais causadores da degradação das terras agrícolas, provocando expressivos prejuízos à sociedade. Em virtude desses danos, torna-se fundamental o desenvolvimento de técnicas que permitam o aumento da eficiência das práticas para a conservação do solo. Com esse objetivo, desenvolveu-se um modelo para o dimensionamento e a locação de sistemas de terraceamento em nível, utilizando modelos digitais de elevação do terreno gerados em sistemas de informações geográficas (SIG). A fim de possibilitar a aplicação do modelo desenvolvido, elaborou-se um software que permite a realização das interações necessárias para o dimensionamento do sistema. Os resultados obtidos mostram que o modelo oferece a vantagem de permitir o dimensionamento de cada terraço, considerando as condições existentes na área específica que irá contribuir com o escoamento superficial para o mesmo. A outra vantagem do modelo desenvolvido está na possibilidade de realização de simulações, permitindo a observação e o acompanhamento, de maneira fácil e objetiva, das mudanças provocadas no sistema de terraceamento, em função da alteração nas características de uso e manejo do solo.
\end{abstract}

PALAVRAS-CHAVE: erosão hídrica, conservação do solo e água, planejamento integrado.

\section{MODEL TO DESIGN LEVEL TERRACING SYSTEMS}

\begin{abstract}
Water erosion is one of the main problems of agricultural lands degradation, causing largess damages to the society. Because of these damages, it becomes necessary the development of techniques that allow the increase of the efficiency of soil conservation practices. With this objective, a model was developed for design and location of level terracing systems using digital models of elevation of the land generated in geographic information systems (GIS). In order to facilitate the application of the developed model, it was elaborated a software. The results show that the model offers as the principal advantage the design of each terrace considering the existent conditions in the specific area that will contribute with the runoff to itself. The other advantage of the developed model is the possibility of simulations accomplishment, allowing the observation and the accompaniment of the changes caused in the terracing system in function of the changes in the soil use and handling.
\end{abstract}

KEYWORDS: water erosion, soil and water conservation, integrated planning.

\section{INTRODUÇÃO}

A erosão hídrica é a principal forma de ocorrência do processo erosivo nas regiões tropicais, sendo provocada principalmente devido ao impacto direto da água sobre o terreno e pelo excessivo escoamento superficial.

\footnotetext{
${ }^{1}$ Prof. Adjunto, Escola de Agronomia, UFG, Goiânia - GO, Fone: (0XX62) 521.1557, griebeler@yahoo.com.br

${ }^{2}$ Prof. Titular, Departamento de Engenharia Agrícola, UFV, Viçosa - MG, (0XX31) 3899.1912, ffpruski@ufv.br. Bolsista do CNPq.

${ }^{3}$ Bacharel em Informática, M.Sc., aft@ cientec.net

${ }^{4}$ Prof. Adjunto, Departamento de Engenharia Agrícola, UFV, Viçosa - MG, Fone: (0XX31) 3899.1912, dds@ufv.br. Bolsista do CNPq.

Recebido pelo Conselho Editorial em: 30-5-2003

Aprovado pelo Conselho Editorial em: 23-9-2005
} 
Várias são as práticas utilizadas para controlar a erosão hídrica em solos agrícolas, sendo normalmente divididas em práticas edáficas, vegetativas e mecânicas. As práticas mecânicas são aquelas nas quais são utilizadas estruturas artificiais para a redução da energia do escoamento da água, sendo o terraceamento de terras agrícolas a prática mecânica mais difundida e utilizada.

Diversos programas de planejamento integrado do solo e da água têm utilizado o terraceamento como prática fundamental para o controle da erosão. SILVA (1997) descreveu ações realizadas no programa de desenvolvimento rural do Paraná, chamado Paraná Rural, e apresentou estudos comparativos entre bacias hidrográficas nas quais os trabalhos de planejamento e manejo não haviam iniciado e aquelas em que já haviam sido parcialmente e/ou totalmente executados. Os resultados demonstraram reduções progressivas nos índices de turbidez da água à medida que os trabalhos avançavam nas bacias. Esses índices, conforme ROLOFF (1996), atingiram valores médios de 50\%, chegando, em algumas áreas, a reduções da ordem de 80\%. RICHTER (1995) encontrou reduções de $56,4 \%$ nos índices de turbidez e de $10,4 \%$ no custo de tratamento da água apenas com o uso de práticas mecânicas para a conservação do solo.

Apesar de ser uma prática bastante antiga, o terraceamento apresenta ainda dificuldades relativas ao seu uso, sendo sua eficiência dependente do correto dimensionamento do espaço entre terraços e da sua seção transversal. $\mathrm{O}$ espaçamento deve ser estipulado em função do comprimento de rampa para o qual a água escoada superficialmente não atinja energia suficiente para erodir o solo.

Diferentes metodologias utilizadas para estabelecer o espaçamento entre terraços no Brasil encontram-se disponíveis na literatura, as quais são normalmente funções da declividade do terreno e das características do solo. LOMBARDI NETO et al. (1994) desenvolveram metodologia que, além das características topográficas e do terreno, utiliza informações sobre o uso e o manejo do solo, permitindo, dessa forma, que alterações nessas características interfiram no dimensionamento do sistema.

Para terraços posicionados em nível, toda a água escoada deverá ficar retida para posterior infiltração; nesse sentido, a altura que o camalhão do terraço deve apresentar, é função do volume de água que escoa superficialmente. PRUSKI et al. (1997) desenvolveram um modelo para a obtenção da lâmina máxima de escoamento superficial que permite a obtenção do volume de escoamento superficial a ser retido por terraços posicionados em nível. Esse modelo permite, em função do tipo e da forma do camalhão do terraço, determinar a altura que o mesmo deve apresentar. GRIEBELER et al. (2001) realizaram comparações entre os resultados por esse modelo e aqueles observados no campo, obtendo coeficientes de correlação de 0,97 e diferença percentual média de 1,7. DENARDIN et al. $(1998,2003)$ realizaram o dimensionamento de sistema de terraceamento em área cultivada sob plantio direto, utilizando o modelo proposto por PRUSKI et al. (1997) e evidenciaram que o modelo respondeu satisfatoriamente, mesmo sob condições de precipitações intensas.

Mesmo com o correto dimensionamento do sistema de terraceamento em nível, sua implantação em terrenos com topografia irregular apresenta dificuldades relacionadas ao relevo, uma vez que os terraços devem acompanhar linhas de mesmo nível e, com a variação na declividade da área, ocorrem também variações no afastamento entre os terraços.

$\mathrm{O}$ uso de técnicas de geoprocessamento permite que se transporte para um ambiente computacional a representação aproximada da natureza que se deseja analisar, ou sobre a qual se deseja modelar, permitindo que as variações sejam utilizadas nos processos de análise.

Nesse sentido, o presente trabalho foi realizado com o objetivo de desenvolver uma metodologia que permita o dimensionamento e a locação em planta de sistemas de terraceamento agrícola em nível, utilizando as técnicas de geoprocessamento e, dessa forma, possibilitar a otimização e a racionalização do uso desses sistemas para a conservação dos solos. 


\section{MATERIAL E MÉTODOS}

A metodologia desenvolvida requer informações do relevo na forma digital (base de dados digitais) e, ainda, o uso dos métodos disponíveis para a determinação do espaçamento entre terraços e cálculo da lâmina de escoamento superficial (base de dados do sistema de terraceamento).

\section{Elaboração da base de dados digitais (BDD)}

A base digital é constituída de um modelo de elevação do terreno (MDE) e de declividade (MDD). Para a geração do MDE, é utilizado um mapa contendo as curvas de nível do terreno, as quais são transformadas para a forma digital por meio de digitalização, gerando um mapa digital no formato vetorial. Essas curvas são então interpoladas, por meio de rotinas específicas presentes em softwares de SIG, gerando imagem no formato raster, a qual corresponde ao MDE. Essa imagem consiste em uma matriz de valores, na qual cada célula é representada por um valor de cota.

A partir do MDE, gera-se o MDD, que consiste em uma imagem que apresenta, em cada célula, o valor da declividade máxima obtida a partir da elevação das células vizinhas.

\section{Base de dados do sistema de terraceamento (DST)}

A base de dados do sistema de terraceamento é composta pelas informações necessárias para o cálculo do espaçamento entre terraços e dimensionamento da sua seção transversal. Para o cálculo do espaçamento vertical entre terraços $(\mathrm{EV})$, foi utilizada metodologia desenvolvida por LOMBARDI NETO et al. (1994), de acordo com a seguinte equação:

$$
\mathrm{EV}=0,4518 \mathrm{k} \mathrm{D}^{0,58}\left(\frac{\mathrm{U}+\mathrm{M}}{2}\right)
$$

em que,

$\mathrm{k}$ - coeficiente relacionado ao solo, adimensional;

D - declividade, \%;

$\mathrm{U}$ - fator de uso do solo, adimensional, e

$\mathrm{M}$ - fator de manejo do solo (adimensional).

A altura do terraço foi determinada a partir da metodologia desenvolvida por PRUSKI et al. (1997).

\section{Desenvolvimento da metodologia}

Para a integração da base DST com a BDD, foi desenvolvido um software, o qual teve a finalidade de permitir que a interação entre as duas bases de dados fosse feita de forma fácil e rápida.

Ao usuário caberá definir as informações a serem utilizadas pela metodologia para a determinação do EV e, também, para a determinação da lâmina máxima de escoamento superficial, bem como associar a essas informações a base de dados digitais.

\section{Início do processamento}

O espaçamento entre terraços depende da declividade do terreno, a qual é obtida a partir da média aritmética dos valores contidos no MDD, resultando em um valor de declividade média de toda a área $\left(\bar{D}_{1}\right)$. Uma vez conhecido esse valor, com a equação para cálculo do espaçamento, é obtido o espaçamento vertical inicial $\left(\mathrm{Ev}_{\mathrm{i}}\right)$. $\mathrm{O}$ valor de $\overline{\mathrm{D}}_{1}$ e $E v_{\mathrm{i}}$ são fixos durante todo o processamento.

A cota para início da locação do primeiro terraço na área estudada é obtida subtraindo o valor de $E v_{i}$ da célula de maior cota do MDE. Nos terraços subseqüentes, a cota para o início da locação é obtida subtraindo $\mathrm{Ev}_{\mathrm{i}}$ da cota de locação do terraço anterior, sendo a locação realizada, seguindo-se os valores de mesma cota até que seja encontrado o limite da área. 
Após a demarcação de cada terraço, é determinada sua área de influência $\left(\mathrm{A}_{\mathrm{i}}\right)$, a qual corresponde à área situada entre dois terraços adjacentes ou entre o terraço locado e o limite da área, caso esse esteja localizado em uma das extremidades. Tendo sido isolada essa área, é realizado o cálculo da declividade, por média aritmética simples, apenas na área $\mathrm{A}_{\mathrm{i}}$, obtendo-se novo valor de declividade ( $\left.\overline{\mathrm{D}}_{2}\right)$, a partir do qual é recalculado o espaçamento vertical entre terraços $\left(\mathrm{Ev}_{\mathrm{f}}\right)$. $\mathrm{O}$ valor de $\mathrm{Ev}_{\mathrm{f}}$ é, então, utilizado para a relocação do terraço anteriormente locado. $\mathrm{O}$ valor de $\overline{\mathrm{D}}_{2}$ é variável, sendo seu cálculo realizado para cada novo terraço.

Terminada a locação do terraço, é realizada a procura de regiões, na sua $A_{i}$, nas quais deveriam ter sido locados terraços, mas foram isoladas devido à topografia. Essas regiões foram chamadas de órfãs, sendo chamados de terraços órfãos todos os terraços que devam ser locados nessa área.

Na Figura 1, é apresentado o desenho esquemático de uma área, indicando o ponto para o início da locação, os terraços locados e a ocorrência de um terraço órfão.

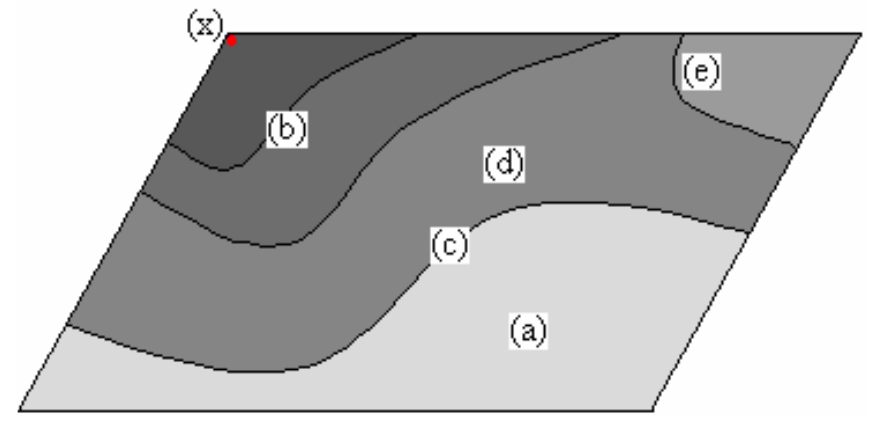

FIGURA 1. Imagem esquemática de uma área indicando a posição do ponto para início da locação (x), a área ainda a ser locada (a), a área com terraços locados (b), o último terraço locado (c) e sua área de influência (d) e a existência de um terraço isolado (órfão) em área interna ao último terraço locado (e).

Para a verificação da existência de regiões órfãs e da necessidade de locação de terraços nessas regiões, é somado o valor de $\mathrm{Ev}_{\mathrm{f}}$ ao último terraço locado, obtendo-se a cota do terraço anterior, sendo esse valor de cota procurado na $\mathrm{A}_{\mathrm{i}}$. A identificação de uma célula com valor de cota semelhante (tomou-se como duas casas decimais, em metros) à cota do terraço anterior indica a possível existência de terraço órfão. O terraço somente é locado quando o local da cota se encontra suficientemente afastado de algum outro terraço (considerado como $3 \mathrm{~m}$ em qualquer direção), o que é feito por meio da análise das células em torno do ponto encontrado.

Esse procedimento é repetido para cada terraço locado, inclusive para procurar terraços órfãos na área isolada pelo próprio terraço órfão locado. Caso não sejam encontrados terraços órfãos, o procedimento de locação continua até ser encontrado o final da área, o qual é determinado quando a subtração do valor de $\mathrm{Ev}_{\mathrm{i}}$ de um terraço recém-locado fornecer cota inferior às cotas existentes na área ainda não locada, tendo em vista que a locação se inicia pelo ponto de cota mais elevada.

Após o término da locação, o sistema fornece um relatório, no qual constam as informações da base de dados do sistema de terraceamento e as informações obtidas da base de dados digitais, como área terraceada, número de terraços locados e informações sobre cada terraço locado. Cada terraço é representado pelo número de ordem e cota da locação, declividade da $\mathrm{A}_{\mathrm{i}}$, comprimento e altura recomendados para a locação. O sistema fornece, também, mapa da área com o sistema de terraceamento locado, permitindo a observação dos resultados obtidos na forma gráfica.

\section{Estudo de caso}

Com o objetivo de avaliar a metodologia desenvolvida, realizou-se estudo de caso, utilizando uma pequena bacia hidrográfica localizada na localidade de Palmital, no município de Viçosa - MG. O 
levantamento foi realizado por topografia digital, e o processamento dos dados foi realizado com o software topográfico Topograph. Os arquivos foram gerados no software AutoCad e, posteriormente, interpolados no software Surfer, a partir do qual puderam ser importados para o software Terraço 2.0. A bacia apresenta área de 3,97 ha e mostra-se bastante íngreme, com declividade média de 56,77\%.

Foram considerados para simulação do Ev, diferentes condições de uso e manejo do solo e, para simulação da altura dos terraços, foram tomadas diferentes taxas de infiltração da água no solo (Ti)*. No cálculo do Ev, consideraram-se a cultura do feijão $(U=0,5)$ e a cultura do milho $(U=1,25)$. Em ambas, o manejo do solo considerado foi do grupo $5^{* *}(\mathrm{M}=2,0)$, e o tipo de solo da área foi tomado como homogêneo e apresentando resistência moderada à erosão $(\mathrm{k}=1,1)$. As Ti utilizadas foram aquelas observadas em campo (60 e $72 \mathrm{~mm} \mathrm{~h}^{-1}$ ), as quais foram tomadas somente para a avaliação da sensibilidade do modelo a esse parâmetro. Com essa finalidade, foi considerada, também, Ti de $20 \mathrm{~mm} \mathrm{~h}^{-1}$. Em nenhuma das situações, procurou-se comparar taxas de infiltração com sistemas de manejo.

As condições de precipitação utilizadas para a obtenção da lâmina de escoamento superficial e a determinação da altura do camalhão dos terraços (Ht) correspondem àquelas referentes a Viçosa - MG, obtidas utilizando o software Plúvio ${ }^{* * *}$. Esse software permite obter a equação de chuvas intensas para qualquer localidade do Paraná, Minas Gerais, São Paulo, Rio de Janeiro e Espírito Santo. O período de retorno considerado foi de 10 anos.

\section{RESULTADOS E DISCUSSÃO}

Na Figura 2, são apresentados o MDE da área e a disposição dos terraços locados quando o dimensionamento foi realizado para as culturas do feijão (2a) e do milho (2b) e, nas Tabelas 1 e 2, os valores numéricos referentes a cada terraço locado.
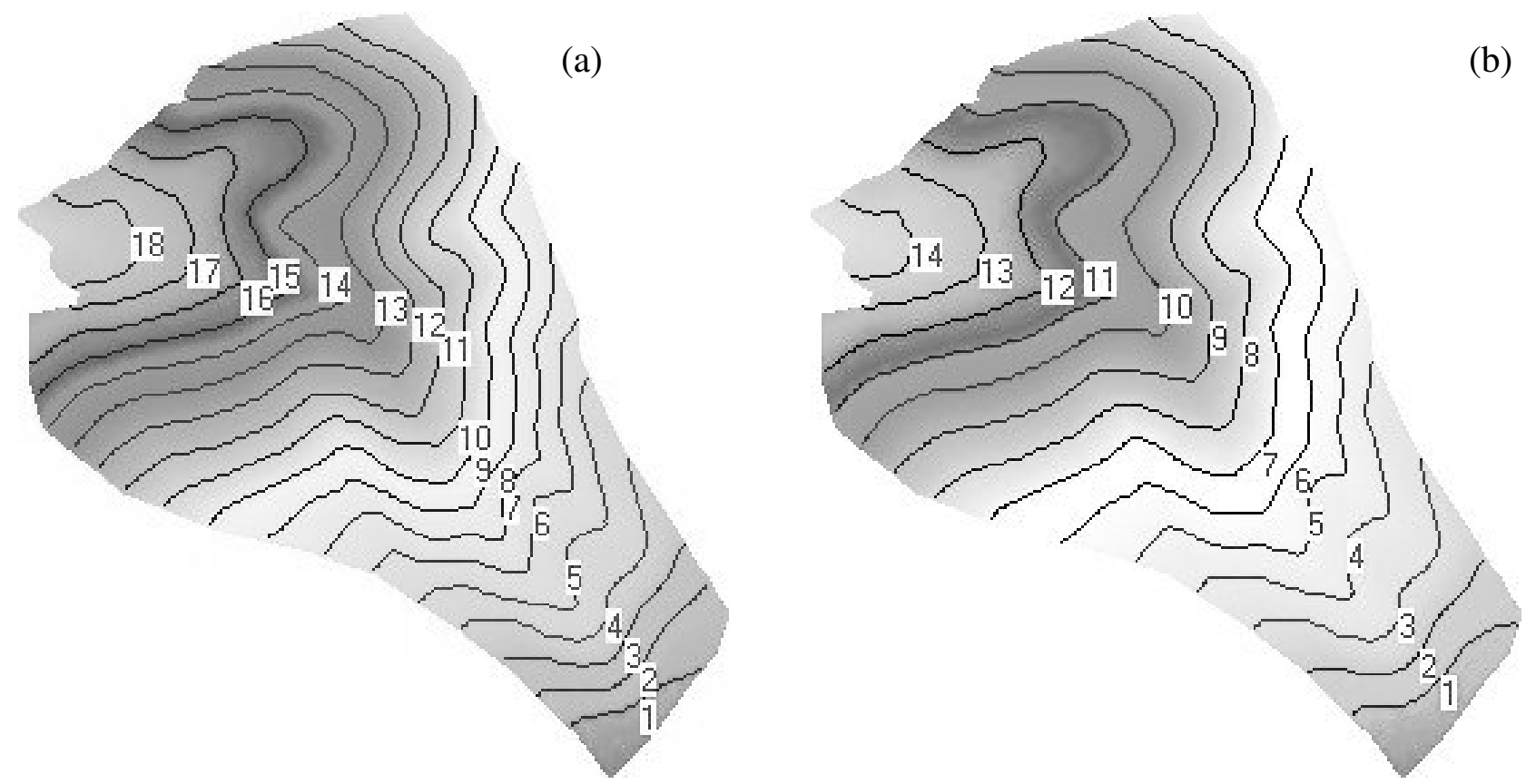

FIGURA 2. Modelo digital de elevação (MDE) e disposição de terraços na área de aplicação do modelo desenvolvido com a cultura do feijão (a) e do milho (b).

\footnotetext{
* As taxas de infiltração utilizadas no modelo correspondem à taxa de infiltração estável (Ti) ou VIB

** Plantio sem revolvimento do solo, com restos culturais mantidos sobre o terreno (LOMBARDI NETO et al., 1994)

*** Disponível em www.ufv.brldealgprh
} 
TABELA 1. Relação dos terraços locados, cota de locação, comprimento, área de influência e altura dos terraços para condições de dimensionamento, considerando a cultura do feijão e diferentes taxas de infiltração de água no solo.

\begin{tabular}{ccccccccc}
\hline \multirow{2}{*}{$\mathrm{n}^{\mathrm{o}}$} & \multirow{2}{*}{ Cota $(\mathrm{m})$} & $\begin{array}{c}\mathrm{Ev}^{*} \\
(\mathrm{~m})\end{array}$ & $\begin{array}{c}\overline{\mathrm{D}}_{2}{ }^{*} \\
(\mathrm{~m})\end{array}$ & \multicolumn{1}{c}{$\begin{array}{c}\mathrm{L}^{*} \\
(\mathrm{~m})\end{array}$} & $\begin{array}{c}\mathrm{A}_{\mathrm{i}}{ }^{*} \\
\left(\mathrm{~m}^{2}\right)\end{array}$ & \multicolumn{3}{c}{ Altura do Camalhão dos Terraços $(\mathrm{m})$} \\
\hline 1 & 902,10 & 3,85 & 23,20 & 55,36 & 646 & 0,28 & 0,30 & 0,48 \\
2 & 896,80 & 5,37 & 41,26 & 83,93 & 1.040 & 0,32 & 0,34 & 0,57 \\
3 & 889,92 & 6,76 & 61,31 & 95,37 & 917 & 0,31 & 0,34 & 0,55 \\
4 & 884,18 & 5,77 & 46,64 & 128,89 & 1.243 & 0,30 & 0,32 & 0,52 \\
5 & 878,70 & 5,44 & 42,19 & 159,25 & 1.807 & 0,31 & 0,34 & 0,55 \\
6 & 872,28 & 6,31 & 54,45 & 171,57 & 1.788 & 0,31 & 0,34 & 0,56 \\
7 & 865,46 & 6,82 & 62,23 & 196,09 & 1.801 & 0,30 & 0,33 & 0,54 \\
8 & 858,46 & 7,06 & 66,08 & 227,16 & 2.076 & 0,31 & 0,33 & 0,55 \\
9 & 851,68 & 6,87 & 63,05 & 243,02 & 2.289 & 0,31 & 0,33 & 0,55 \\
10 & 844,94 & 6,80 & 61,86 & 263,78 & 2.468 & 0,31 & 0,33 & 0,55 \\
11 & 838,18 & 6,83 & 62,42 & 307,23 & 3.088 & 0,31 & 0,34 & 0,56 \\
12 & 831,45 & 6,85 & 62,64 & 300,86 & 2.931 & 0,31 & 0,34 & 0,56 \\
13 & 824,85 & 6,71 & 60,51 & 295,87 & 2.923 & 0,31 & 0,34 & 0,56 \\
14 & 818,14 & 6,81 & 62,10 & 281,63 & 2.825 & 0,31 & 0,34 & 0,56 \\
15 & 811,50 & 6,66 & 59,77 & 240,49 & 2.675 & 0,32 & 0,35 & 0,58 \\
16 & 805,40 & 6,25 & 53,47 & 180,21 & 2.213 & 0,33 & 0,36 & 0,59 \\
17 & 798,86 & 6,24 & 53,45 & 107,08 & 1.752 & 0,36 & 0,40 & 0,67 \\
18 & 793,36 & 5,28 & 39,99 & 75,98 & 1.175 & 0,34 & 0,37 & 0,62 \\
\hline
\end{tabular}

* Ev - espaçamento vertical; $\overline{\mathrm{D}}_{2}$ - declividade média em $\mathrm{A}_{\mathrm{i}} ; \mathrm{L}$ - comprimento do terraço; $\mathrm{A}_{\mathrm{i}}$ - área de influência; $\mathrm{Ti}_{1}$ $72 \mathrm{~mm} \mathrm{~h}^{-1} ; \mathrm{Ti}_{2}-60 \mathrm{~mm} \mathrm{~h}^{-1} ; \mathrm{Ti}_{3}-20 \mathrm{~mm} \mathrm{~h}^{-1}$.

TABELA 2. Relação dos terraços locados, cota de locação, comprimento, área de influência e altura dos terraços para condições de dimensionamento, considerando a cultura do milho e diferentes taxas de infiltração de água no solo.

\begin{tabular}{|c|c|c|c|c|c|c|c|c|}
\hline \multirow{2}{*}{$\mathrm{n}^{\mathrm{o}}$} & \multirow{2}{*}{ Cota $(\mathrm{m})$} & \multirow{2}{*}{$\begin{array}{l}\mathrm{Ev}^{*} \\
(\mathrm{~m})\end{array}$} & \multirow{2}{*}{$\begin{array}{l}\overline{\mathrm{D}}_{2}{ }^{*} \\
(\mathrm{~m})\end{array}$} & \multirow{2}{*}{$\begin{array}{c}\mathrm{L}^{*} \\
(\mathrm{~m})\end{array}$} & \multirow{2}{*}{$\begin{array}{l}\mathrm{A}_{\mathrm{i}^{*}} \\
\left(\mathrm{~m}^{2}\right)\end{array}$} & \multicolumn{3}{|c|}{ Altura do Camalhão dos Terraços (m) } \\
\hline & & & & & & $\mathrm{Ti}_{1}$ & $\mathrm{Ti}_{2}$ & $\mathrm{Ti}_{3}$ \\
\hline 1 & 900,32 & 5,63 & 28,46 & 76,00 & 1.125 & 0,30 & 0,34 & 0,55 \\
\hline 2 & 892,03 & 8,30 & 55,57 & 88,47 & 1.208 & 0,33 & 0,37 & 0,61 \\
\hline 3 & 884,17 & 7,70 & 48,77 & 128,85 & 1.579 & 0,31 & 0,35 & 0,57 \\
\hline 4 & 876,81 & 7,33 & 44,86 & 160,83 & 2.406 & 0,33 & 0,37 & 0,61 \\
\hline 5 & 868,29 & 8,58 & 58,86 & 182,00 & 2.312 & 0,32 & 0,37 & 0,60 \\
\hline 6 & 859,13 & 9,15 & 65,72 & 225,96 & 2.688 & 0,32 & 0,37 & 0,59 \\
\hline 7 & 850,07 & 8,97 & 63,54 & 246,89 & 3.118 & 0,32 & 0,37 & 0,61 \\
\hline 8 & 841,28 & 8,82 & 61,65 & 312,44 & 3.691 & 0,31 & 0,36 & 0,59 \\
\hline 9 & 832,51 & 8,91 & 62,70 & 298,99 & 3.920 & 0,33 & 0,38 & 0,61 \\
\hline 10 & 823,64 & 8,76 & 60,93 & 294,46 & 4.003 & 0,33 & 0,38 & 0,62 \\
\hline 11 & 814,85 & 8,87 & 62,27 & 266,15 & 3.697 & 0,33 & 0,38 & 0,63 \\
\hline 12 & 806,68 & 8,30 & 55,50 & 198,56 & 3.198 & 0,35 & 0,40 & 0,66 \\
\hline 13 & 798,73 & 8,08 & 52,98 & 105,42 & 2.248 & 0,38 & 0,44 & 0,73 \\
\hline 14 & 791,90 & 6,74 & 38,83 & 67,26 & 1.435 & 0,36 & 0,42 & 0,69 \\
\hline
\end{tabular}

* Ev - espaçamento vertical; $\overline{\mathrm{D}}_{2}$ - declividade média em $\mathrm{A}_{\mathrm{i}} ; \mathrm{L}$ - comprimento do terraço; $\mathrm{A}_{\mathrm{i}}$ - área de influência; $\mathrm{Ti}_{1}$ $72 \mathrm{~mm} \mathrm{~h}^{-1} ; \mathrm{Ti}_{2}-60 \mathrm{~mm} \mathrm{~h}^{-1} ; \mathrm{Ti}_{3}-20 \mathrm{~mm} \mathrm{~h}^{-1}$. 
Observa-se, na Figura 2, que existem diferenças no número e, conseqüentemente, no espaçamento entre terraços, os quais se apresentam mais próximos na Figura 2a e mais afastados na Figura 2b. Esse afastamento deve-se, principalmente, à alteração dos fatores de cultivo considerados para a realização dos cálculos de espaçamento entre terraços. A variação na declividade também pode ter interferido, uma vez que esta é obtida individualmente para cada terraço. Esse comportamento é inerente à metodologia utilizada para o cálculo do espaçamento entre terraços, na qual os fatores de cultivo e a declividade do terreno são utilizados diretamente na equação que determina o espaçamento.

Em ambas as imagens apresentadas na Figura 1, observa-se que o espaçamento horizontal entre terraços consecutivos é variável, indicando que a topografia é desuniforme. Essas variações podem acarretar diversos problemas, principalmente se o espaçamento entre terraços tornar-se muito reduzido, prejudicando a movimentação de máquinas, elevando os custos e dificultando as operações de cultivo. Essa medida indica também que a tomada do espaçamento horizontal entre terraços como indicativa da configuração do sistema no campo não é recomendada, tendo em vista que a mesma se altera ao longo da área, sendo constante apenas sob condições topográficas uniformes.

A variação no espaçamento horizontal entre terraços consecutivos ao longo da área irá influenciar na área que contribui para o escoamento superficial para um determinado terraço. Normalmente, essa área é obtida tomando-se o espaçamento horizontal entre terraços, obtido para uma determinada declividade, a qual é então multiplicada pelo comprimento do terraço. Esse fato, conforme verificado, não corresponde à condição real encontrada em terrenos de topografia irregular. A alteração dessa área poderá acarretar problemas quanto à capacidade de acumulação de água pelo sistema. Quando a área calculada for inferior à área real, o sistema poderá ser subdimensionado, aumentando os riscos de falha do sistema e, quando a área for superior à área real, o sistema será superdimensionado, elevando os custos de implantação.

Comparando-se a declividade média da área total com a declividade média da área de interesse, apresentadas nas Tabelas 1 e 2, observa-se que, enquanto a primeira é de 56,77\%, a $\bar{D}_{2}$ variou de 23,20 a $66,08 \%$ e de 28,46 a 65,72 para os sistemas dimensionados para a cultura do feijão e milho, respectivamente. Esses valores resultaram em valores de Ev de 3,85 e 7,06 m para a área do feijão e de 5,63 e 9,15 m para o milho. Considerando-se o dimensionamento com base na declividade média de toda a área, obteríamos Ev de 6,47 se a cultura considerada fosse o feijão e de 8,40 se fosse o milho. Percebe-se, por esses valores, que a variabilidade da área interfere expressivamente nos resultados, indicando a importância do cálculo do Ev baseado em $\bar{D}_{2}$, podendo vir a reduzir os riscos de falha do sistema ou de superdimensionamento.

A consideração da variabilidade do relevo e da $\bar{D}_{2}$ pode também vir a reduzir os riscos de ocorrência de erosão entre terraços, tendo em vista que são utilizados parâmetros individuais para cada terraço, adequando-se mais às condições do terreno, aumentando, assim, a eficiência e a confiabilidade no uso dessa prática para a conservação do solo.

As áreas de contribuição ao escoamento para cada terraço também se mostraram bastante variáveis e, como a altura dos terraços é dependente dessa área, a mesma também variou. A altura do camalhão do terraço, no entanto, também é dependente do comprimento do terraço, pois, para uma mesma área, porém com terraço de maior comprimento, a altura do camalhão pode ser menor, visto que o volume de água a ser acumulada aumenta. Pode-se observar esse fato nos terraços 2 e 4 da Tabela 2, em que a $A_{i}$ praticamente dobrou seu valor, e a altura recomendada para o camalhão permaneceu a mesma, o que se deve ao fato de o comprimento também ter praticamente dobrado. Para esses mesmos terraços, o Ev apresentou diferença de quase $1 \mathrm{~m}$. Esses valores reforçam a necessidade da consideração da variabilidade espacial para a realização de projetos de terraceamento. 
A consideração de parâmetros independentes para o dimensionamento de cada terraço requer, entretanto, maior atenção por parte do técnico responsável pela implantação do sistema, uma vez que o espaçamento vertical é diferenciado entre terraços consecutivos.

A comparação entre o dimensionamento, considerando a cultura do feijão e a cultura do milho, foi observada de maneira mais evidente no número de terraços locados. Para as condições adotadas no dimensionamento e considerando a cultura do feijão, observou-se a necessidade de 18 terraços na área e comprimento total de $3.413,75 \mathrm{~m}$ de terraços. Já, para a cultura do milho, foi observada a necessidade de 14 terraços e 2.652,28 m de terraços. A diferença no número de terraços locados está diretamente relacionada à metodologia utilizada para o cálculo do Ev, sendo que a cultura do milho, devido às suas características, favorece menos a ocorrência da erosão quando comparada com o feijão, possibilitando, devido a esse fato, a locação de menor número de terraços.

O comprimento total também está relacionado ao número de terraços a serem implantados, bem como à cota de locação que pode, em alguns casos, fazer com que os terraços sejam mais compridos. Esse fato pode ser facilmente observado quando se compara o primeiro terraço locado na Figura $2 \mathrm{a}$ e $2 \mathrm{~b}$, respectivamente.

As diferentes taxas de infiltração tomadas no estudo de caso permitiram avaliar o modelo quanto a sua sensibilidade a esse parâmetro. Observou-se que maiores taxas de infiltração proporcionaram menores alturas aos camalhões dos terraços, como seria esperado, uma vez que a lâmina escoada é menor. Apesar de as taxas de infiltração utilizadas não estarem relacionadas a diferentes tipos de manejo do solo, ressalta-se que formas de manejo que favoreçam a infiltração, reduzem os riscos de erosão e permitem a implantação de sistemas de custo mais baixo.

Quando se compara a altura dos camalhões dos terraços obtida com as simulações realizadas com as culturas consideradas, verifica-se que, para a cultura do feijão, os terraços se mostraram mais baixos do que para a cultura do milho. Esse fato está relacionado ao número de terraços, uma vez que menor número faz com que esses estejam mais afastados, fazendo com que a $A_{i}$ seja maior, refletindo em maior volume de água a ser retido pelo terraço.

Os resultados apresentados demonstram a possibilidade da utilização do modelo para realizar simulações com critérios preestabelecidos e analisar rapidamente o que seria obtido no campo com a implantação do sistema de terraceamento para a conservação do solo. Dessa forma, o modelo permite, também, que seja verificada a influência que as alterações realizadas nas formas de manejo do solo e nos cultivos exercem na implantação desse tipo de sistema para a conservação do solo.

A utilização da metodologia visando à implantação de um sistema de terraceamento requer os valores apresentados nos relatórios, como aqueles das Tabelas 1 e 2 . As imagens com o sistema locado (Figuras 1 e 2) são apenas ilustrativas.

\section{CONCLUSÕES}

A metodologia desenvolvida permite o dimensionamento e a locação do sistema de terraceamento em nível, considerando as variações topográficas existentes no terreno, a realização de simulações dos efeitos que as alterações no uso e no manejo do solo têm sobre o dimensionamento e a locação do sistema de terraceamento em nível, e a estimativa do comprimento total de terraços.

\section{REFERÊNCIAS}

DENARDIN, J.E.; BERTON, A.; TROMBETTA, A.; KOCHHANN, R.A.; FALCÃO, H. Terraceamento em lavoura planejada sob plantio direto. In: REUNIÃO BRASILEIRA DE MANEJO E CONSERVAÇÃO DO SOLO E DA ÁGUA, 1998, Fortaleza. Resumos... Fortaleza: Sociedade

Brasileira de Ciência do Solo/Universidade Federal do Ceará, 1998. p.198-9. 
DENARDIN, J.E.; KOCHHANN, R.A.; BERTON, A.; TROMBETTA, A.; FALCÃO, H.

Terraceamento em plantio direto. Disponível em: <http://www.cnpt.embrapa.br/p_co08.htm>. Acesso em: $1^{\underline{0}}$ maio 2003.

GRIEBELER, N.P.; PRUSKI, F.F.; MARTINS JÚNIOR, D.; SILVA, D.D. Avaliação de um modelo para estimativa da lâmina máxima de escoamento superficial. Revista Brasileira de Ciência do Solo, Viçosa - MG, v.25, n.2, p.411-17, 2001.

LOMBARDI NETO, F.; BELINAZZI JUNIOR, R.; LEPSCH, I.F.; OLIVEIRA, J.B.; BERTOLINI, D. GALETI, P.A.; DRUGOWICH, M.I. Terraceamento agrícola. Campinas: Secretaria da Agricultura e Abastecimento do Estado de São Paulo, CATI, 1994. 39 p. (Boletim Técnico, 206).

PRUSKI, F.F.; FERREIRA, P.A.; RAMOS M.M.; CECON, P.R. A model to design level terraces. Journal of Irrigation and Drainage Enginnering, New York, v.123, n.1, p.8-12, 1997.

RICHTER, A.S. Contribuições do controle da erosão dos solos em microbacias hidrográficas para a melhoria da qualidade da água no Rio Ampére. In: CONGRESSO BRASILEIRO DE CIÊNCIA DO SOLO, 25., 1995, Viçosa - MG, Resumos... Viçosa - MG: Sociedade Brasileira de Ciência do Solo, 1995. p.2111-13.

ROLOFF, G. A experiência paranaense no manejo de microbacias hidrográficas. In: ALVAREZ V.V.H.; FONTES, L.E.F.; FONTES, M.P.F. (Eds.). O solo nos grandes domínios morfoclimáticos do Brasil e o desenvolvimento sustentado. Viçosa - MG: SBCS/UFV/DPS, 1996. p.781-96.

SILVA, J.C.C. Planejamento integrado em microbacias hidrográficas. In: SILVA D.D., PRUSKI, F.F. (Eds.). Recursos hídricos e o desenvolvimento sustentável da agricultura. Brasília: MMA/SRH/ ABEAS, Viçosa - MG: UFV/DEA, 1997. p.115-28. 